Original Article

\title{
Assessment of Marine Water Quality in Quang Binh and Quang Ngai Provinces for Tourism Development Activities
}

\author{
Nguyen Hai Phong ${ }^{1}$, Truong Quang Hai $^{2}$, Nguyen Quang Tuan ${ }^{1, *}$, Ho Xuan Anh Vu ${ }^{1}$ \\ ${ }^{1}$ University of Sciences, Hue University, 77 Nguyen Hue Street, Hue city, Vietnam \\ ${ }^{2}$ VNU Institute of Vietnamese Studies and Development Sciences, Vietnam National University, Hanoi \\ 336 Nguyen Trai, Hanoi, Vietnam
}

Received 18 May 2020

Revised 28 May 2020; Accepted 27 June 2020

\begin{abstract}
This article assessing status of water quality in coastal areas of Quang Binh and Quang Ngai provinces for the purpose of tourism development. The results of research showed that water quality at monitoring sites at the beaches in Quang Binh and Quang Ngai provinces met requirements of QCVN 10-MT:2015/BTNMT for beach and underwater sport. Particularly with parameters such as: turbidity (NTU) at LS2, LS7 and LS14 sites exceed standards of ASEAN and chemical oxygen demand (COD) was increased. However, COD is not regulations in QCVN 10MT: 2015 / BTNMT, ASEAN and Australia but when compared with QCVN 01: 2009 / BYT are more than two times. This can influence for health when exposed to coastal water in tourist areas.
\end{abstract}

Keywords: water quality in coastal areas, Quang Binh and Quang Ngai provinces.

\footnotetext{
* Corresponding author.

E-mail address: tuanhuegis@gmail.com

https://doi.org/10.25073/2588-1094/vnuees.4634
} 


\title{
Đánh giá chất lượng nước biển các tỉnh Quảng Bình và Quảng Ngãi cho hoạt động phát triển du lịch
}

\author{
Nguyễn Hải Phong ${ }^{1}$, Trương Quang Hải ${ }^{2}$, Nguyễn Quang Tuấn ${ }^{1, *}$, Hồ Xuân Anh Vũ ${ }^{1}$ \\ ${ }^{I}$ Truòng Đại học Khoa học, Đại học Huế, 77 Nguyễn Huệ, thành phố Huế, Việt Nam \\ ${ }^{2}$ Viện Việt Nam học và Khoa học Phát triển, Đại học Quốc gia Hà Nội, 336 Nguyễn Trãi, Hà Nội, Việt Nam
}

Nhận ngày 18 tháng 5 năm 2020

Chỉnh sửa ngày 28 tháng 5 năm 2020; Chấp nhận đăng ngày 27 tháng 6 năm 2020

\begin{abstract}
Tóm tắt: Bài báo này đánh giá hiện trạng chất lượng nước $(\mathrm{CLN})$ vùng ven biển hai tỉnh Quảng Bình và Quảng $\mathrm{Ngãi}$ nhằm mục đích phát triển hoạt động du lịch. Các kết quả nghiên cứu cho thấy rằng $\mathrm{CLN}$ tại các điểm quan trắc ven biển và ven đảo ở tỉnh Quảng Bình và tỉnh Quảng $\mathrm{Ngãi}$ nằm trong giới hạn cho phép của QCVN 10-MT:2015/BTNMT cho mục đích vùng bãi tắm, thể thao dưới nước. Riêng với các thông số như: độ đục (NTU) tại một số vị trí LS2, LS7 và LS14 vượt tiêu chuẩn của ASEAN và nhu cầu oxy hóa học (COD) có xu thế tăng. Tuy nhiên, COD không được quy định trong QCVN 10-MT:2015/BTNMT, ASEAN và Australia, song khi so sánh với QCVN 01:2009/BYT đều lớn hơn gấp hai lần trở lên. Điều này có thể ảnh hưởng đến sức khỏe khi tiếp xúc với nước biển ven bờ tại các khu du lịch.
\end{abstract}

Tù khóa: chất lượng nước vùng ven biển, du lịch biển, Quảng Bình, Quảng Ngãi.

\section{Mở đầu}

Du lịch là một ngành kinh tế dịch vụ tổng hợp, mang nội dung văn hóa và nhân văn sâu sắc, đem lại hiệu quả nhiều mặt về kinh tế, văn hóa, xã hội, môi trường, chính trị và đối ngoại. Theo Tổ chức du lịch Thế giới, du lịch đóng vai trò quan trọng để đạt được tất cả 17 mục tiêu của phát triển bền vững (UNWTO, 2017) [1]. Trong đó, du lịch biển đang tăng trưởng với tốc độ nhanh $[2,3]$.

Việt Nam là một quốc gia ven biển có nguồn tài nguyên du lịch phong phú và độc đáo. Nhận thức rõ vị thế quan trọng của du lịch và tận dụng ưu thế về tài nguyên, trong những năm vừa qua, ngành du lịch biển Việt Nam đã tăng trưởng khá trong cả doanh thu và số lượt khách du lịch, đóng góp quan trọng vào sự phát triển kinh tế biển. Tuy vậy, du lịch vùng ven biển và biển đảo Việt Nam đang phải đối mặt với nhiều khó khăn, thách thức, đe dọa tính bền vững về kinh tế, xã hội và môi trường. Để giải quyết vấn đề này, đề tài khoa học cấp quốc gia "Luận cứ khoa học về tổ chức không gian, xác lập mổ hình và đề xuất giải pháp phát triển du lịch bền vững khu vực ven biển và biển đảo Việt Nam”, mã số KC.09.09/16-20 đã được triển khai, trong đó đã lựa chọn một số khu vực thuộc hai tỉnh Quảng Bình và Quảng Ngãi để thực hiện trong khuôn khổ nghiên cứu này.

Trên thế giới đã có những hướng dẫn quản lý chất lượng và quan trắc nước biển $[4,5]$. Ở Việt Nam hiện trạng môi trường nước biển đã được phân tích, đánh giá qua các kết quả quan trắc $[6,7]$. Song còn ít các nghiên cứu đánh giá chất lượng nước cho hoạt động phát triển du lịch.

Quảng Bình có thành phố Đồng Hới là một trong những trung tâm du lịch chính của vùng Bắc Trung Bộ, hội tụ và lan tỏa các tuyến du lịch

\footnotetext{
* Tác giả liên hệ.

Địa chỉ email: tuanhuegis@gmail.com

https://doi.org/10.25073/2588-1094/vnuees.4634
} 
nội tỉnh và liên tỉnh. Từ vị trí trung tâm chính trị, hành chính của tỉnh Quảng Bình, Đồng Hới kết nối thuận lợi với các khu vực khác theo trục Bắc - Nam và với khu vực đồi núi theo trục Đông Tây, đặc biệt nối kết với Khu Di sản Thế giới Phong Nha - Kẻ Bàng cách 40 km về phía Tây.

Quảng Ngãi có Lý Sơn là huyện đảo có mật độ dân số cao, có cảnh quan thiên nhiên kỳ vĩ hiện hữu dấu ấn của hoạt động núi lửa, có truyền thống lịch sử - văn hóa đặc sắc gắn với quá trình bảo vệ chủ quyền biển đảo của Tổ quốc.

Quảng Bình và Quảng Ngãi đều mang tính chất khí nhiệt đới gió mùa với sự phân hóa sâu sắc mùa khô và mùa mưa. Ở Quảng Bình mùa mưa tập trung từ tháng 9 đến tháng 11 và kéo đến tháng 3 năm sau, chiếm khoảng $80 \%$ lượng mưa cả năm. Mùa khô từ tháng 4 đến tháng 8 với gió Tây Nam khô nóng. Quảng Ngãi có mùa mưa kéo dài từ tháng 9 đến tháng 2 năm sau, lượng mưa tập trung trong mùa mưa khoảng $71 \%$. Mùa khô kéo dài từ tháng 3 đến tháng 8 , thời tiết khô và nóng do chịu ảnh hưởng của gió mùa Tây Nam. Mùa khô cũng là mùa du lịch với đông khách đến tham quan, nghỉ dưỡng và tắm biển, gây ảnh hưởng mạnh đến chất lượng nước biển. Vì vậy, việc đo đạc và lấy mẫu nước biển để phân tích, đánh giá được thực hiện vào ngày 27-28 tháng Bảy tại Quảng Bình và ngày 2-3 tháng Tám năm 2019 tại Quảng Ngãi.

Bài viết này tập trung đánh giá chất lượng môi trường nước ven biển góp phần xác lập luận cứ cho phát triển du lịch bền vững ở tỉnh Quảng Bình và Quảng Ngãi.

\section{Tài liệu và phương pháp nghiên cứu}

\subsection{Thông tin của các vị trí quan trắc}

Đánh giá chất lượng nước biển ven bờ phục vụ cho mục đích tắm biển và thể thao dưới nước, do đó độ sâu lấy mẫu khoảng từ 1,0 đến $1,5 \mathrm{~m}$ tại tất cả các vị trí quan trắc.

\subsection{Co sở tài liệu và phương pháp nghiên cứu}

Chuẩn bị mẫu: trong đợt khảo sát và lấy mẫu, tiến lấy mẫu và phân tích nước ven biển tại tỉnh
Quảng Bình: 02 khu vực là bãi biển Nhật Lệ (08 mẫu) và Bảo Ninh (10 mẫu), ngoài ra còn 02 mẫu tại Vũng Chùa, 05 mẫu tại bãi tắm Đá Nhảy, 04 mẫu tại cầu Nhật Lệ và cầu Quán Hàu để so sánh. Tại tỉnh Quảng Ngãi: lấy mẫu 02 khu vực là Đảo Lý Sơn (11 mẫu) và Đảo Bé (10 mẫu). Tại hai khu vực Bãi biển Mỹ Khê, cách thành phố Quảng Ngãi $15 \mathrm{~km}$ về phía đông và bãi tắm Ghềnh Yến, cách $30 \mathrm{~km}$ là những bãi biển có tiềm năng cho khai thác du lịch biển. Tại hai khu vực này đều lấy 03 mẫu. Thêm vào đó, khu vực cảng Sa Kỳ cũng lấy 02 mẫu với mục đích so sánh. Như vậy tổng số mẫu được lấy và phân tích tại hai tỉnh Quảng Bình và Quảng Ngãi là 62 mẫu.

Quy cách lấy mẫu và bảo quản mẫu: tuân thủ quy định của TCVN 6663-3:2016-Hướng dẫn bảo quản và xử lý mẫu nước [8]. Các mẫu được bảo quản trong chai nhựa PET (polyetylenterephtalat) sạch và nước đá lạnh, vận chuyển về và phân tích tại phòng thí nghiệm của Khoa Hóa học, Trường Đại học Khoa học, Đại học Huế.

Các phương pháp phân tích chất lượng nước: các phương pháp tiêu chuẩn Việt Nam, các phương pháp tiêu chuẩn phân tích nước và nước thải (SMEWW-Standard Methods for Examination of Water and Wastewater, APHA, 2017) [9]. Các thông số nhiệt độ, pH, độ dẫn điện, $\mathrm{EC}$ (tồng chất rắn hòa tan, TDS và độ mặn, $\mathrm{NaCl}$ $\%$ o), độ đục (NTU) và oxy hòa tan được đo tại hiện trường với thiết bị Horiba U52, Nhật Bản. Các thông số tổng chất rắn lơ lửng (TSS), nhu cầu oxy hóa học (COD), amoni (N - $\mathrm{NH}_{4}^{+}$), photphat $\left(\mathrm{P}-\mathrm{PO}_{4}{ }^{3-}\right)$, tổng photpho $(\mathrm{TP})$, tổng nitơ $(\mathrm{TN})$ và Sunfat $\left(\mathrm{SO}_{4}{ }^{3-}\right)$ được thực hiện tại Phòng thí nghiệm Môi trường (Bộ môn Hóa phân tích, khoa Hóa học, Trường Đại học Khoa học, Đại học Huế). Hai thông số asen (As) và tổng coliform (TC) thực hiện bởi Trung tâm Quan trắc Tài nguyên và Môi trường, tỉnh Thừa Thiên Huế (173 Phạm Văn Đồng, thành phố Huế).

Chất lượng nước (CLN) được đánh giá qua từng thông số bằng cách so sánh kết quả thu được $\left(\mathrm{x}_{\mathrm{TB}} \pm \mathrm{Sd}\right.$ với $\mathrm{x}_{\mathrm{TB}}$ là trung bình số học và $\mathrm{Sd}$ là độ lệch chuẩn) với các giá trị giới hạn được quy định trong QCVN 10-MT:2015/BTNMT (viết tắt là $\mathrm{QCVN10)}$ về $\mathrm{CLN}$ ven biển [10], QCVN 
01:2009/BYT (viết tắt là QCVN01) về CLN ăn uống [11] và QCVN 02:2009/BYT (viết tắt là QCVN02) về CLN sinh hoạt [12]. Hệ số biến động $(\mathrm{CV})$ đối với mỗi thông số $\mathrm{CLN}$ cũng được tính toán: $\mathrm{CV}=\mathrm{Sd}^{*} 100 / \mathrm{x}_{\mathrm{TB}}$.

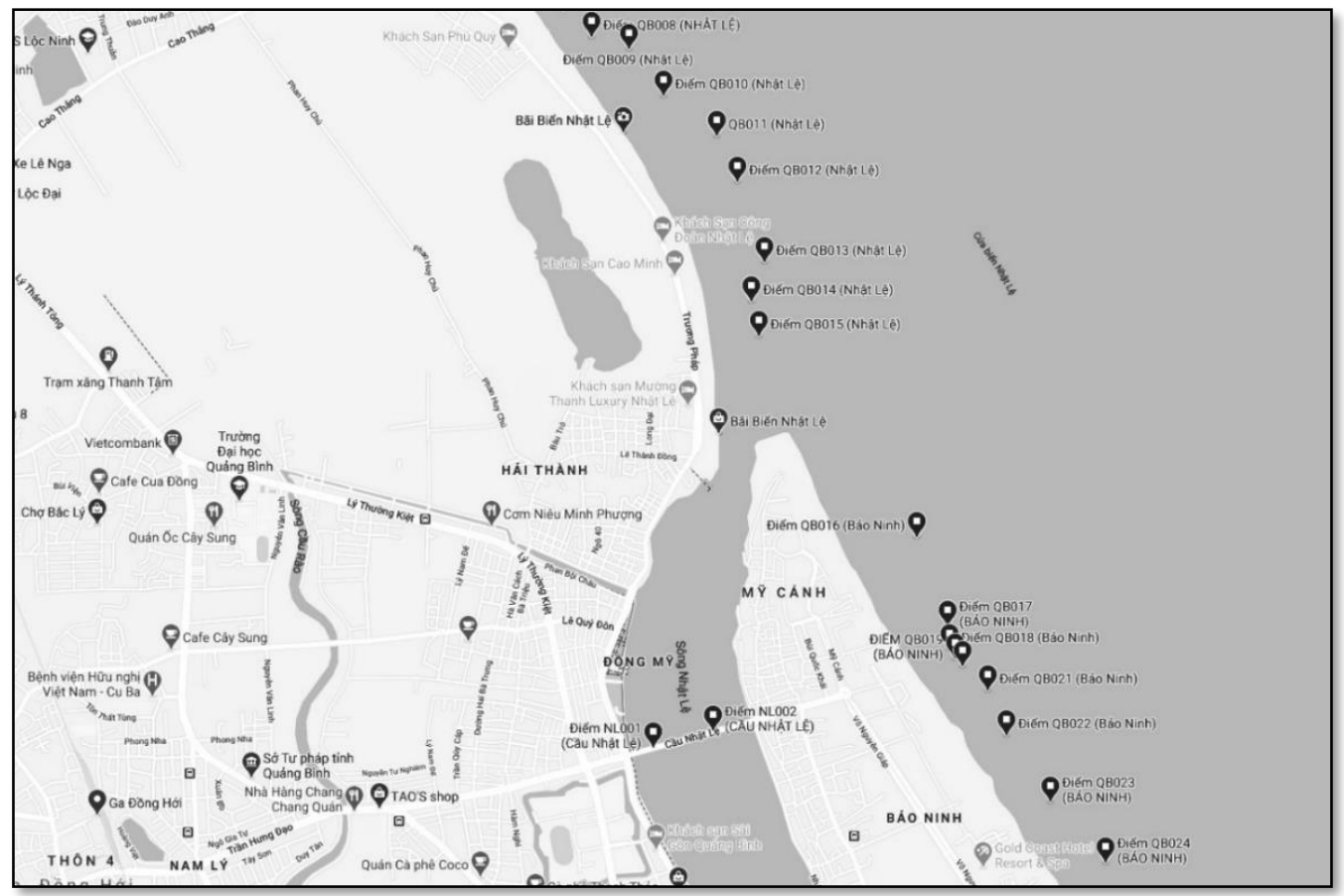

Hình 1. Sơ đồ điểm thu mẫu vùng ven bờ biển Nhật Lệ, tỉnh Quảng Bình. (Nguồn bản đồ: Google Maps và điểm thực địa).
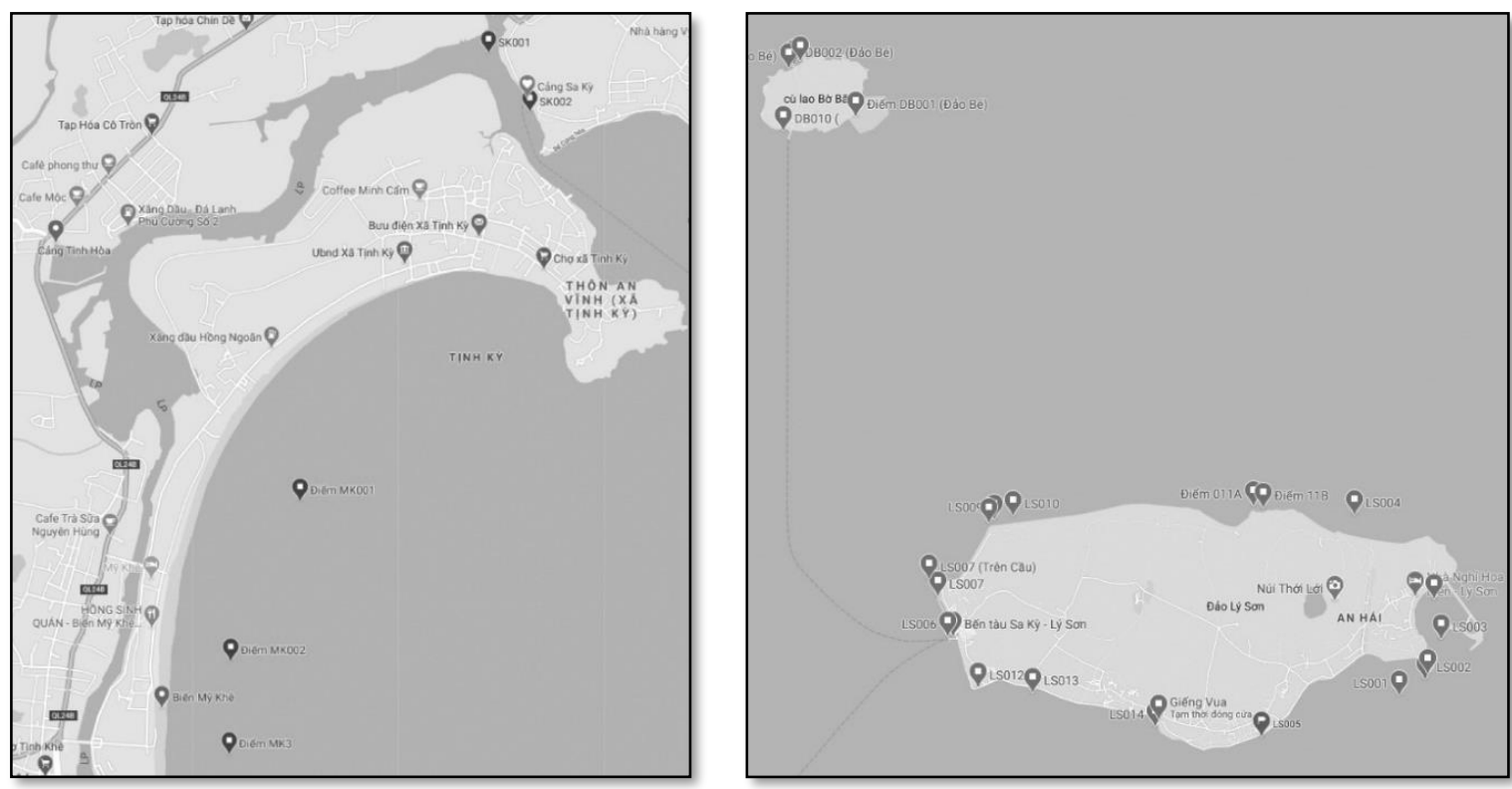

Hình 2. Sơ đồ điểm thu mẫu vùng ven bờ biển Mỹ Khê và Đảo Lý Sơn, tỉnh Quảng Ngãi. (Nguồn bản đồ: Google Maps và điểm thực địa). 


\section{Kết quả và thảo luận}

\section{1. Đánh giá chung về chất lượng nước vùng} biển các tỉnh Quảng Bình và Quảng Ngãi đối với du lịch

Nhận xét chung về chất lượng nước ven biển tỉnh Quảng Bình và Quảng Ngãi

Các kết quả phân tích cho thấy độ mặn tại các khu vực ven biển tỉnh Quảng Bình là 33,7 \pm $0,4 \% 0(\mathrm{n}=27)$ trừ hai vị trí tại Cầu Quán Hàu do đi sâu vào đất liền gần $20 \mathrm{~km}$. Như vậy, độ mặn tại các điểm quan trắc tương đương với các vùng biển nước nông. Riêng tại hai điểm tại Cầu Quán Hàu là $25,8 \%$ là khá phù hợp với mục đích nuôi trồng thủy hải sản. Đối với các vị trí quan trắc tại tỉnh Quảng Ngãi, độ mặn là 34,9 \pm 0,5 \%o (n = 31) trừ hai vị trí tại cảng Sa Kỳ do đi sâu vào đất liền gần hơn $5 \mathrm{~km}$ và chịu tác động của nước ngọt. Như vậy, độ mặn tại các điểm quan trắc tương đương với các vùng biển nước sâu. Điều này cũng hợp lý là do phần lớn vị trí quan trắc là vùng đảo Lý Sơn, chiếm 75,8\% \% Riêng tại hai điểm tại hai vị trí cảng Sa Kỳ độ mặn là 17,2 và $18,0 \%$.

Các thông số dinh dưỡng là tổng nitơ $(\mathrm{TN})$ và tổng photpho (TP) tại các vị trí ở hai tỉnh Quảng Bình và Quảng Ngãi là khá thấp, giá trị trung bình dao động từ $0,02 \mathrm{mg} / \mathrm{L}$ đến 0,07 $\mathrm{mg} / \mathrm{L}$. Nhưng mức độ dao động của hai thông số

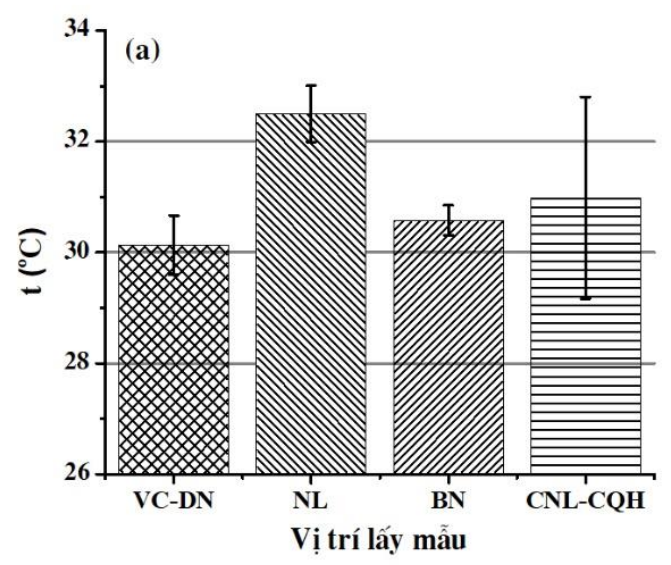

này là rất lớn với hệ số biến động (Coefficient of Variation - CV) đều lớn hơn $50 \%$ đến $64,2 \%$. Riêng đối với thông số P-PO4 đều nhỏ hơn giới hạn phát hiện $(\mathrm{GHPH}), \mathrm{GHPH}$ của thông số PPO4 là $0,026 \mathrm{mg} / \mathrm{L}$.

Trong đợt khảo sát này, đề tài chỉ tập trung phân tích Asen (As) nhưng trong tất cả 62 mẫu trong khu vực nghiên cứu đều nhỏ hơn giới hạn phát hiện là $0,0018(\mathrm{mg} / \mathrm{L})$.

Tóm lại, các thông số như độ mặn (độ dẫn điện, $\mathrm{EC}$ và tổng chất rắn hòa tan, $\mathrm{TDS}$ ), $\mathrm{TN}, \mathrm{TP}$, $\mathrm{P}^{-} \mathrm{PO}_{4}$ và $\mathrm{As}$ mặc dù không được quy định trong QCVN 10:2015/BTNMT, những tất cả đều khá thấp. Chính vì vậy, trong báo cáo này chỉ tập trung vào một số thông số cơ bản và có trong quy định QCVN 10:2015/BTNMT cho mục đích "Vùng bãi tắm, thể thao dưới nước".

\subsection{Nhiệt độ}

Trong toàn vùng quan trắc bao gồm 29 vị trí tại Quảng Bình và 33 vị trí tại Quảng Ngãi với nhiệt độ trung bình là $31,1 \pm 0,8\left({ }^{\circ} \mathrm{C}\right), \mathrm{n}=29$ và $31,3 \pm 0,4\left({ }^{\circ} \mathrm{C}\right)$, với $\mathrm{n}=33$. Qua đó thấy rằng nhiệt độ dao động không đáng kể và thay đồi không nhiều theo không gian tại hai vùng nghiên cứu. So sánh với kết quả nghiên cứu của Lê Thị Vinh (2013) [13] tại đảo Phú Quốc không có sự khác biệt rõ ràng.

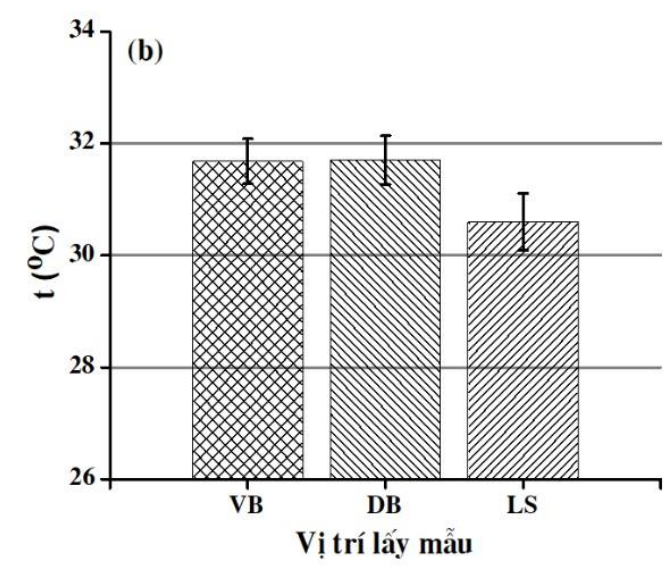

Hình 3. Biến thiên thông số nhiệt độ $\left(\mathrm{t},{ }^{\circ} \mathrm{C}\right)$ tại vùng ven biển tỉnh Quảng Bình (a) và Quảng Ngãi (b). 
Các bãi tắm ven biển và tiếp xúc với đất liền có xu thế cao hơn do chịu ảnh hưởng nhiệt độ của đất liền. Riêng tại 04 vị trí, tại cầu Nhật Lệ và cầu Quán Hàu có nhiệt độ chênh lệch xấp xỉ $3^{\circ} \mathrm{C}$. Sự chênh lệch này dễ dàng nhận thấy tại cầu Nhật Lệ gần cửa biển hơn so với cầu Quán Hàu do nằm sâu trong lục địa và vì vậy, nhiệt độ cao hơn.

Tại các vị trí ở đảo Bé và bãi tắm Nhật Lệ có nhiệt độ cao hơn so với đảo Lý Sơn và bãi tắm Bảo Ninh. Điều này cũng có thể giải thích là phụ thuộc vào thời điểm đo tại hiện trường và vi khí hậu khác nhau sẽ dẫn đến nhiệt độ thay đổi giữa các điểm quan trắc có khác nhau, nhưng không nhiều. Nhiệt độ trung bình thấp chênh lệch xấp xỉ khoảng $2^{\circ} \mathrm{C}$.

\subsection{Thông số $\mathrm{pH}$}

Giá trị pH hoàn toàn không thay đổi, điều

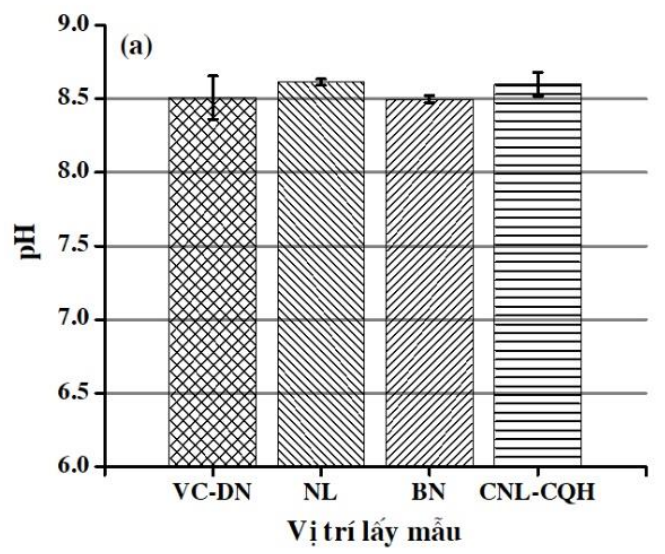

này thông qua giá trị trung bình là $8,6 \pm 0,1, \mathrm{n}=$ 29 đối với các điểm quan trắc tại Quảng Bình và $8,0 \pm 0,1$, với $n=33$ tại Quảng Ngãi. Tất cả các kết quả đều nằm trong giới hạn cho phép của QCVN 10:2015/BTNMT. Nhìn chung, tại hai vùng biển Quảng Bình và Quảng $\mathrm{Ngãi}$ có sự khác nhau khoảng 0,5 đơn vị $\mathrm{pH}$.

Kết quả này là khá phù hợp với $\mathrm{pH}$ của nước biển, bởi vì môi trường nước biển được xem là hệ đệm cacbonat gần như không thay đổi. Tại các điểm $\mathrm{SK} 02$ và $\mathrm{DB} 08$, giá trị $\mathrm{pH}$ là 7,7 và thấp hơn so với các điểm còn lại. Kết quả nghiên cứu của Phạm Hữu Tâm (2018) từ năm 2013 đến 2017 tại ba vùng ven biển Nha Trang, Vũng Tàu và Rạch Giá [14] tương đương với vùng ven biển Quảng Ngãi, nhưng thấp hơn so với vùng ven biển tỉnh Quảng Bình.

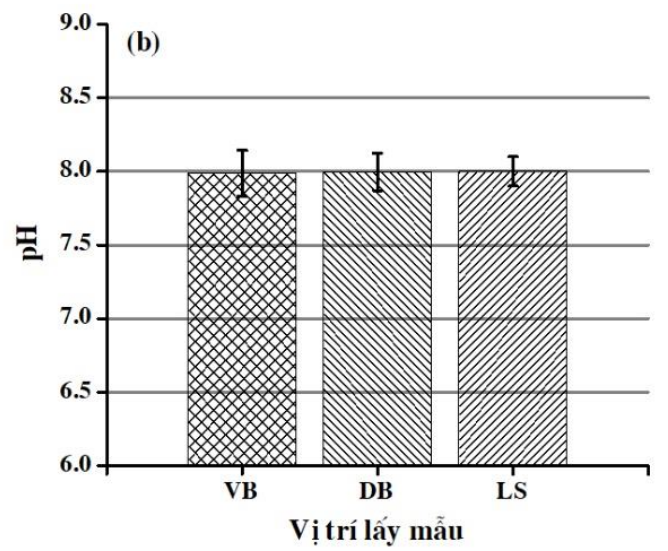

Hình 4. Sự biến động của thông số pH tại vùng ven biển tỉnh Quảng Bình (a) và Quảng Ngãi (b).

\subsection{Chất hũu co}

Dựa vào kết quả phân tích tại Quảng Bình cho thấy giá trị DO đều thỏa mãn QCVN 10:2015/BTNMT (4 mg/L) cho mục đích sử dụng "Vùng bãi tắm, thể thao dưới nước". Tuy nhiên khi so sánh kết quả phân tích $\mathrm{DO}$ và COD lại nhận thấy kết quả khác thường tại hai vùng biển Nhật Lệ và Bảo Ninh với giá trị $\mathrm{DO}$ và giá trị $\mathrm{COD}$ đều cao và cao hơn so với hai vùng còn lại. Sự khác biệt có thể là do hai thông số $\mathrm{DO}$ và $\mathrm{COD}$ khá nhỏ. Khi xem xét với thông số $\mathrm{DO}$ giữa các vùng quan trắc nhận thấy, vùng Vũng Chùa và Đá Nhảy là thấp nhất. Trong quá trình quan trắc, tại vùng này có các mũi đất liền nhô ra biển và làm cản trở gió và sóng, do vậy có thể $\mathrm{DO}$ thấp.

Giá trị DO trung bình tại ba (03) vùng quan trắc lần lượt là: vùng biển ven bờ (sát đất liền): $6,6 \pm 0,7(\mathrm{n}=8)$; Đảo Bé: $6,4 \pm 0,3(\mathrm{n}=10)$ và Đảo Lý Sơn: 6,8 $\pm 0,4(\mathrm{n}=15)(\mathrm{mg} / \mathrm{L})$. Như vậy, vùng biển sát đất liền có giá trị $\mathrm{DO}$ dao động lớn nhất. Riêng tại hai vị trí $\mathrm{SK} 1$ và $\mathrm{SK} 2$ gần cầu cảng giá trị $\mathrm{DO}$ là thấp nhất $(\approx 6 \mathrm{mg} / \mathrm{L})$. Trong khi đó, cũng tại hai vị trí này giá trị COD lại rất cao $(\approx 10 \mathrm{mg} / \mathrm{L})$. Nguyên nhân là do khu vực gần cầu cảng tập trung nhiều thuyền đánh cá của cư 
dân, nơi tiếp nhận các loại nước chất thải và cả chất thải rắn.

Giá trị COD không được quy định trong QCVN 10:2015/BTNMT, nhưng nếu so sánh với QCVN 10:2008/BTNMT (đã được thay thế bằng QCVN 10:2015/BTNMT), quy định của Bộ Y tế QCVN 01:2009/BYT-Chất lượng nước ăn uống (2,0 mg/L) và QCVN 02:2009/BYT-Chất lượng nước sinh hoạt $(4,0 \mathrm{mg} / \mathrm{L})$ thì tại tất cả các vị trí quan trắc đều lớn hơn giới hạn cho phép. Như vậy, giá trị này vẫn có thể ảnh hưởng đến sức khỏe của người dân khi tắm biển và chơi thể thao dưới nước. Kết quả quan trắc cho thấy giá trị COD tại các vùng quan trắc như: Vũng Chùa, Đá Nhảy (Quảng Bình) và Ghềnh Yến, Mỹ Khê và đảo Lý Sơn (Quảng Ngãi) không có sự khác nhau, khoảng 5,0 mg/L. Riêng Đảo Bé, giá trị
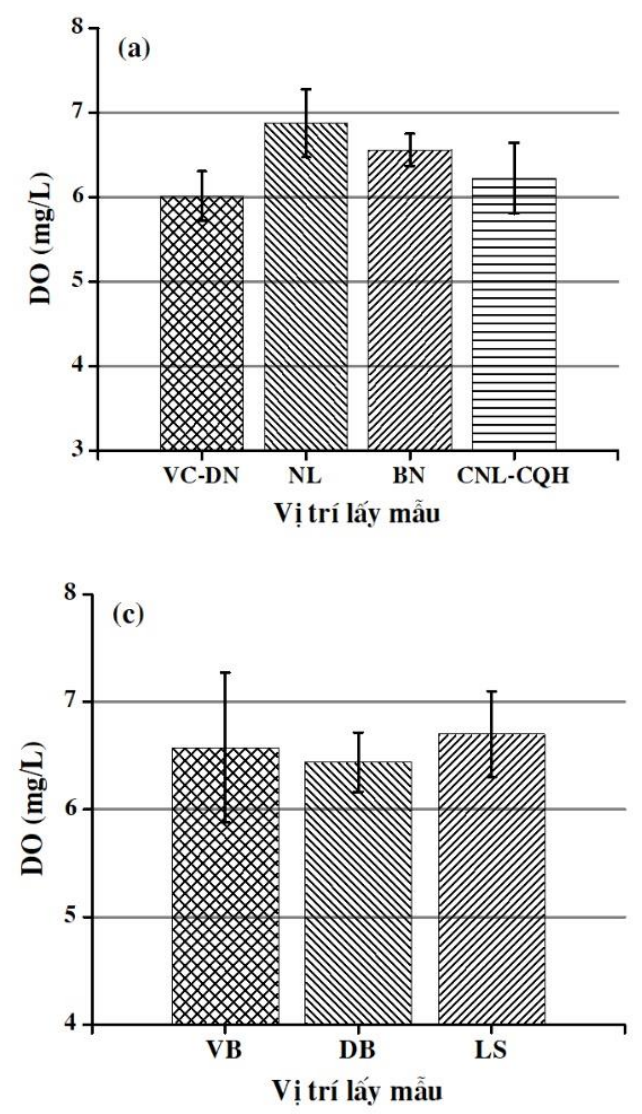

COD là thấp nhất với $3,89 \pm 0,71(\mathrm{n}=10)$ và có hệ số biến động khá thấp là $18,2 \%$. Đặc biệt với hai bãi biển Nhật Lệ và Bảo Ninh tại Thành phố Đồng Hới (Quảng Bình) lại cho kết quả COD khá cao $(6,6 \pm 1,4, \mathrm{n}=18)$ và cao nhất trong các vị trí quan trắc. Điều này có thể nhận thấy, tại thời điểm quan trắc có nhiều nhà hàng và dịch vụ ăn uống ngay ven biển đang hoạt động và vì vậy, dẫn đến sự ô nhiễm chất hữu cơ do nước thải và chất thải rắn.

So sánh với nghiên cứu của tác giả Nguyễn Đình Nguyên (2018) [15] tại vùng ven biển Quảng Bình thì kết quả phân tích thông số $\mathrm{BOD}_{5}$ trong nghiên cứu này thấp hơn khoảng 1,2 lần, nhưng COD lại cao hơn khá nhiều, gấp gần 2,0 lần.
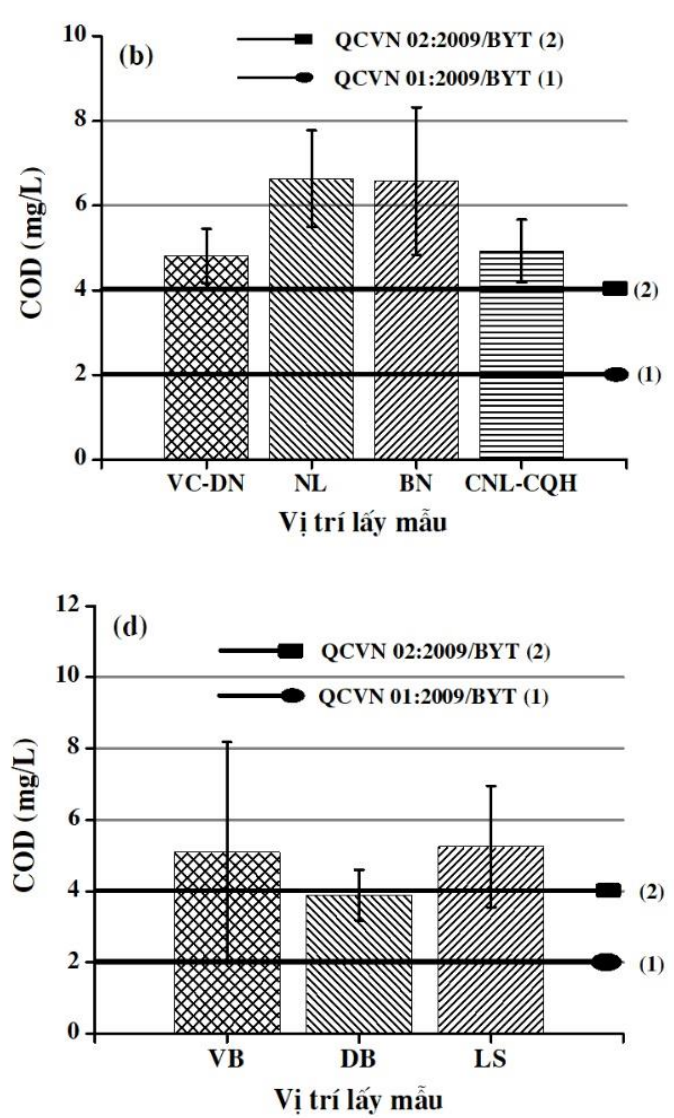

Hình 5. Sự biến động của thông số DO và COD tại vùng ven biển tỉnh Quảng Bình $(\mathrm{a}, \mathrm{b})$ và Quảng Ngãi $(\mathrm{c}, \mathrm{d})$. 


\subsection{Tổng chất rắn lo lủng và độ đục}
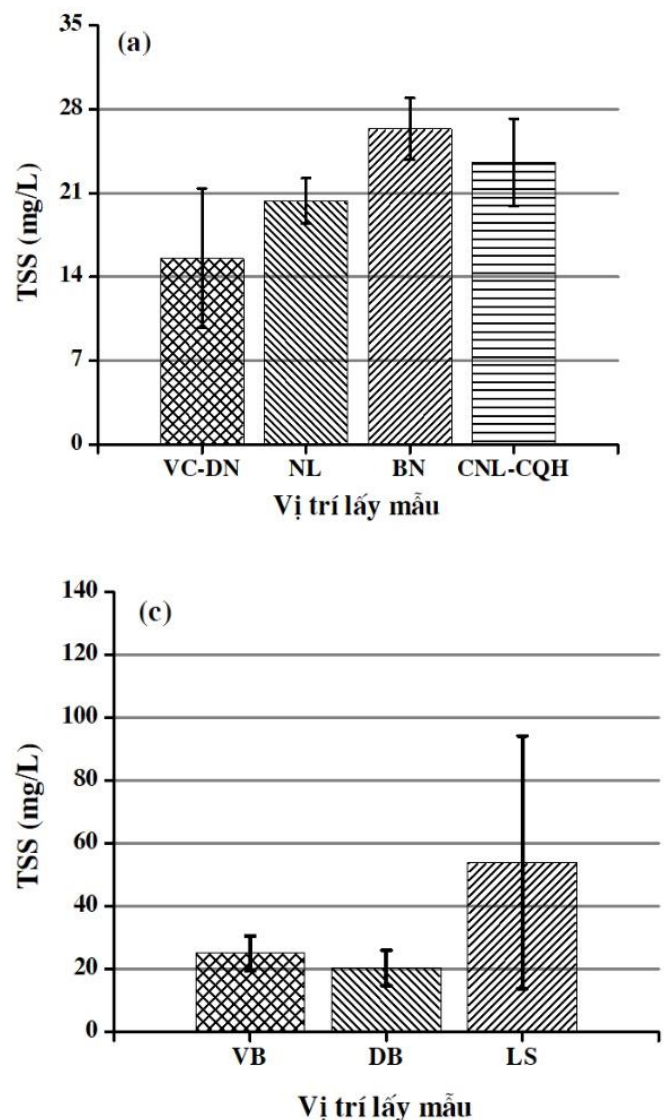
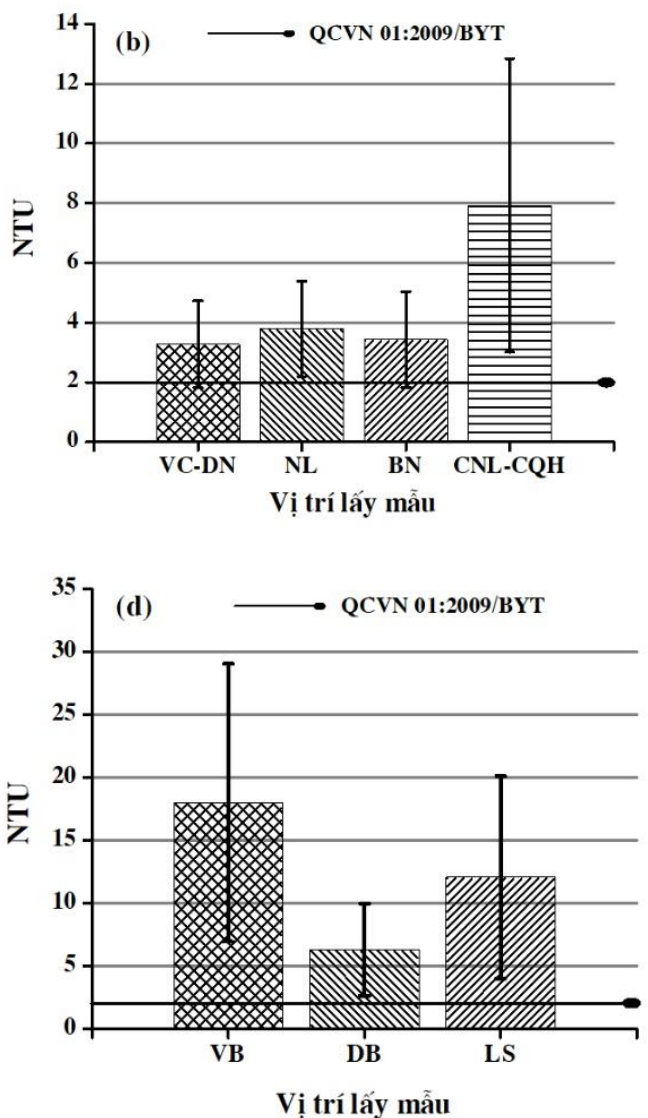

Hình 6. Sự biến động của thông số TSS và NTU tại vùng ven biển tỉnh Quảng Bình (a, b) và Quảng Ngãi (c, d).

Theo QCVN 10:2015/BTNMT quy định thông số tổng chất rắn lơ lửng (TSS) là $50 \mathrm{mg} / \mathrm{L}$, như vậy kết quả phân tích tại 29 vị trí tại Quảng Bình và các vị trí Ghềnh Yến $(\mathrm{n}=3)$, Mỹ Khê $(\mathrm{n}$ $=3)$ và đảo $B e ́(n=10)$ tại Quảng $\mathrm{Ngãi}$ đều nằm dưới giới hạn cho phép. Trong khi đó, đảo Lý Sơn sự biến động khá rộng với giá trị nhỏ nhất và lớn nhất lần lượt là 17,8 và $136 \mathrm{mg} / \mathrm{L}$. Giá trị trung bình là 54,0 $\pm 40,2(\mathrm{n}=15)$. Đặc biệt các vị trí LS13, LS14 và LS15 lớn hơn từ 2,0 đến 2,5 lần so với QCVN 10:2015/BTNMT. Điều này có thể giải thích là trong thời điểm lấy mẫu, sóng biển khá lớn có thể làm khuấy trộn lớp trầm tích bề mặt và do đó, giá trị TSS tăng. Như vậy, việc dựa vào thông số TSS để đánh giá một phần nào đó rất phụ thuộc vào thời gian lấy mẫu, hướng gió và điều kiện vi khí hậu tại vùng nghiên cứu.
Ngoài ra, khi xem xét đến thông số NTU, không được quy định trong QCVN 10:2015/ BTNMT, nhưng theo QCVN01:2009/ BYT - Quy chuẩn kỹ thuật quốc gia về chất lượng nước ăn uống thì tất cả các vị trí đều lớn hơn 2 và do đó, vẫn có khả năng ảnh hưởng đến sức khỏe của người dân tại tất cả các bãi tắm ven biển tỉnh Quảng Bình và Quảng Ngãi.

So sánh với kết quả của Phạm Hữu Tâm (2018) [14], khi đánh giá qua thông số TSS từ 2013 đến 2017, nhận thấy kết quả phân tích TSS cao hơn so với vùng ven biển Nha Trang, nhưng nhỏ hơn so với vị trí Vũng Tàu và Rạch Giá. Riêng đảo Lý Sơn tương đương với vị trí Rạch Giá, năm 2013 là 54,73 mg/L và năm 2016 là $142,9 \mathrm{mg} / \mathrm{L}$. 


\subsection{Amoni}

Kết quả phân tích thông số amoni $\left(\mathrm{N}-\mathrm{NH}_{4}\right)$ trong các bảng từ 01 đến 04 cho thấy tất cả các giá trị đều nhỏ hơn rất nhiều so với quy định là 0,5 mg/L với QCVN 10:2015/BTNMT. Kết quả tại hai vùng ven biển Nhật Lệ và Bảo Ninh đều có giá trị gần như không thay đổi và tương đương nhau $(0,01$ $\mathrm{mg} / \mathrm{L})$. So với vùng biển Vũng Chùa và Đá Nhảy nồng độ amoni cao hơn, với giá trị trung bình là $0,02 \pm 0,01 \mathrm{mg} / \mathrm{L}(\mathrm{n}=7)$. Đối với vùng ven biển Quảng Ngãi, giá trị trung bình tại các điểm quan trắc là $0,018 \pm 0,010 \mathrm{mg} / \mathrm{L}(\mathrm{n}=33)$.

Đối với vị trí Cầu Quán Hàu (Quảng Bình), thì tại vị trí CQH02 có nồng độ amoni khá cao $(0,07, \mathrm{mg} / \mathrm{L})$. Điều này là do tại vị trí này người dân có nuôi trồng thủy hải sản và vùng xung quanh có khá nhiều hộ dân sinh sống. Chính vì

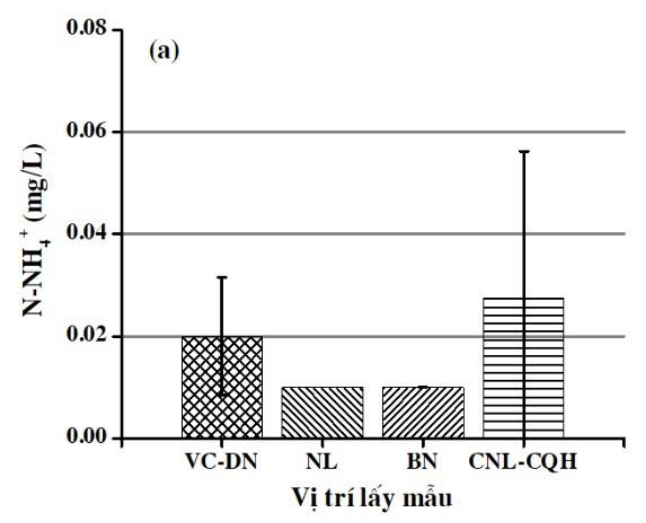

vậy, các loại chất thải sinh hoạt cũng như nuôi trồng thủy hải sản đã ảnh hưởng đến chất lượng nước trong đó có amoni. Ở Quảng Ngãi, tại hai điểm là SK2 và LS15 có giá trị amoni cao hơn so với các điểm khác $(\geq 0,04 \mathrm{mg} / \mathrm{L})$ khoảng từ 4 đến 5 lần. Đây là các điểm có tiềm năng ô nhiễm amoni cao. Bởi vì Khu vực điểm SK2 thuộc cảng Sa Kỳ là nơi cư trú của các tàu thuyền và do vậy, các chất thải là nguyên nhân chính gây nên sự gia tăng này, tương tự như thông số COD. Đối với điểm LS15 ven đảo Lý Sơn, đây cũng là nơi cư trú của nhiều tàu thuyền. Điều này làm cho thông số amoni và COD $(\approx 10 \mathrm{mg} / \mathrm{L})$ tăng đáng kể. Như vậy, vùng biển ven đất liền và ven đảo có thể bị tác động bởi sinh hoạt và dịch vụ ven biển như nhà hàng, dịch vụ du lịch và chất thải từ cửa sông.

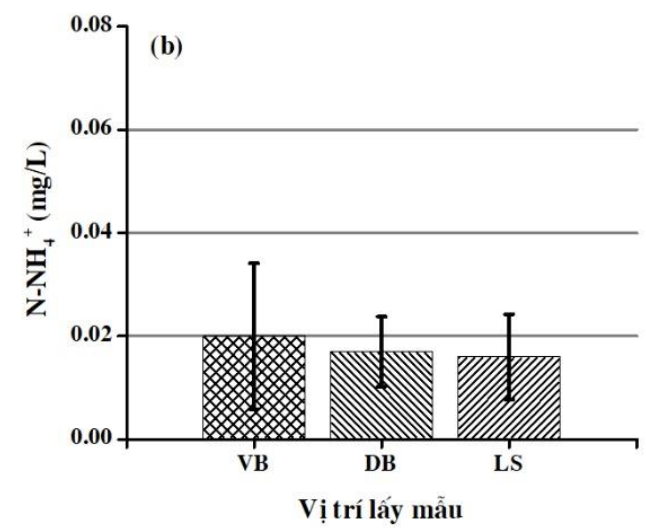

Hình 7. Sự biến động của thông số N-NH4 tại vùng ven biển tỉnh Quảng Bình (a) và Quảng Ngãi (b).
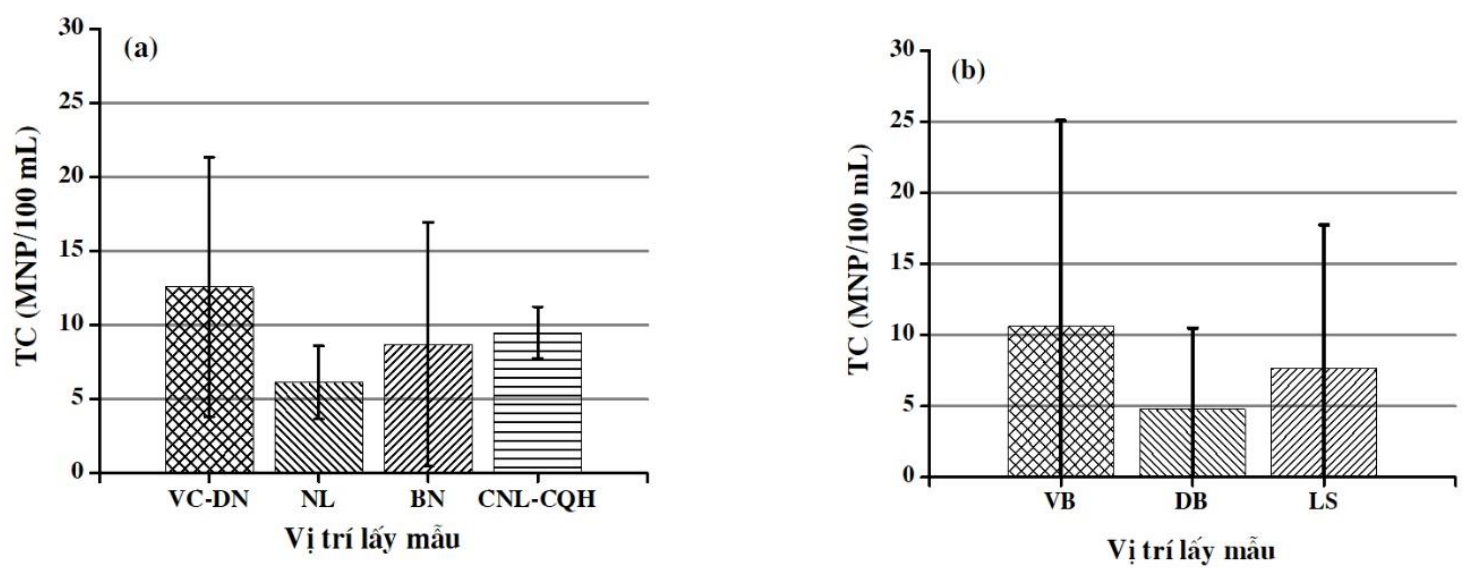

Hình 8. Sự biến động của thông số Tổng Coliform tại vùng ven biển tỉnh Quảng Bình (a) và Quảng Ngãi (b). 


\subsection{Tổng Coliform}

Kết quả phân tích TC trong 29 mẫu tại Quảng Bình và 33 mẫu tại Quảng Ngãi đều có giá trị nhỏ hơn rất nhiều lần, khoảng xấp xỉ 100 lần so với QCVN 10:2015/BTNMT (1000 $\mathrm{MNP} / 100 \mathrm{~mL})$. Như vậy có thể cho rằng vùng ven biển tại Quảng Bình và Quảng Ngãi chưa có dấu hiệu ô nhiễm vi sinh vật gây bệnh. Các điểm SK1, SK2 và LS15 có giá trị TC cao hơn hẳn so với các điểm quan trắc khác. Điều này hoàn toàn phù hợp với kết quả phân tích các thông số COD và amoni.

\section{Kết luận}

Nghiên cứu này đã phân tích và đánh giá chất lượng nước vùng ven biển tại các bãi tắm của hai tỉnh Quảng Bình và Quảng Ngãi. Kết quả cho thấy, chất lượng nước biển ven bờ và ven đảo vào mùa hè thể hiện qua các thông số: nhiệt độ, độ $\mathrm{pH}$, độ mặn, độ dẫn điện (EC) và tổng chất rắn hòa $\tan (\mathrm{TDS})$, tổng nitơ $(\mathrm{TN})$, tổng photpho (TP), $\mathrm{P}_{-} \mathrm{PO}_{4}, \mathrm{As}$, chất hữu cơ $\left(\mathrm{DO}, \mathrm{BOD}_{5}\right)$, độ đục (NTU), amoni ( $\left.\mathrm{N}-\mathrm{NH}_{4}\right)$, tổng Coliform (TC) đảm bảo chất lượng cho nhu cầu tắm biển và thể thao biển (nằm trong giới hạn cho phép của QCVN 10-MT:2015/BTNMT vùng bãi tắm và thể thao dưới nước) . Song cần lưu ý: tại một số vị trí có xu thế ô nhiễm chất hữu cơ như hai bãi tắm Nhật Lệ và Bảo Ninh tỉnh Quảng Bình, với giá trị $C O D$ là $6,6 \pm 1,4, n=18$ và các vùng như Vũng Chùa, Đá nhảy (Quảng Bình), Ghềnh Yến, Mỹ Khê và đảo Lý Sơn (Quảng Ngãi) có dấu hiệu tiềm năng. Khu vực đảo Lý Sơn, có tổng chất rắn lơ lửng (TSS) ở mức gần với $\mathrm{QCVN}$ 10:2015/BTNMT và một số vị trí cao gấp hai lần so với giới hạn cho phép. Cần có các giải pháp thích hợp hạn chế lượng nước thải và rác thải khu vực ven biển và biển đảo, nhất là vào mùa $\mathrm{du}$ lịch, giữ vệ sinh và an toàn sức khỏe cho du khách, đảm bảo phát triển du lịch bền vững.

\section{Lời cảm ơn}

Bài báo này được hoàn thành trong khuôn khổ của đề tài cấp quốc gia, mã số KC.09.09/1620. Nhóm nghiên cứu xin chân thành cảm ơn.

\section{Tài liệu tham khảo}

[1] UNWTO (2017), World Tourism Organization and United Nations Development Programme, 2017, Tourism And The Sustainable Development Goals Journey To 2030 Highlights, UNWTO, Madrid. pp.34 eISBN: 978-92-844-1934-0|ISBN: 978-92844-1933-3. (www.e-unwto.org/doi/pdf/10.18111/ 97 89284419340).

[2] C. Cvitanovic, E.I. Van Putten, A.J. Hobday, M. Mackay, R. Kelly, J. McDonald, K. Waples, P. Barnes. Building trust among marine protected area managers and community members through scientific research: Insights from the Ningaloo Marine Park, Australia. Marine Policy 93 (2018) 195-206. https://doi.org/10.1016/j.marpol.2018.04. 010.

[3] Silvia Giuliani, Luca G. Bellucci, D.H. Nhon (2018), Chapter 19 - The Coast of Vietnam: Present Status and Future Challenges for Sustainable Development. Published in World Seas: An Environmental Evaluation (2nd Edition), Pages 415-435. eBook ISBN: 9780128052037.

[4] ANZECC, Australian Water Quality Guidelines for Fresh and Marine Waters. National Water Quality Management Strategy Paper No.4, Australian and NewZealand Environment and Conservation Council, Canberra, 1992.

[5] Australian Government, ASEAN Marine Water Quality Management Guidelines and Monitoring Manual. Asean Marine Water Quality Criteria, 2008.

[6] Pham Huu Tam, Application of Water Quality Index to Assess Environmental Quality in Coastal Monitoring Stations in the South Viet Nam in the Last 5 Years (2011-2015), VNU Journal of Science: Earth and Environmental Studies 32 (4) (2017) 36-45. https://js.vnu.edu.vn/EES/article/ view/4062. (in Vietnamese)

[7] Le Van Nam, Duong Thanh Nghi, Nguyen Xuan Sang, Quality assessment of coastal waters in the Northern part of Vietnam, 2016. Journal of marine science and technology (Vietnam Maritime University) 52 (2017) 41-45. https://www. researchgate. net/publication/321509054. (in Vietnamese).

[8] Ministry of Natural Resources and Environment (2016), "TCVN 6663-3:2016 - Water quality Sampling - Part 3: Preservation and handling of water samples", Hanoi 2016. https://vanbanphap luat.co/data/2018/05/310750_tcvn6663-3-2016. pdf. (in Vietnamese).

[9] Rodger B. Baird, Andrew D, Eaton, Eugene W, Rice, (2017), "Standard Methods for the Examination of Water and Wastewater", $23^{\text {rd }}$ 
Edition, American Public Health Association, 800 I Street, NW, Washington, DC 20001-3710, ISSN 55-1979.

[10] Ministry of Natural Resources and Environment (2015), "QCVN 10:2015/BTNMT - National technical regulation on marine water quality", Hanoi 2015. http://www.iph.org.vn/attachments/ article/1010/QCVN\%2010.2015_Nuoc\%20bien.p df. (in Vietnamese).

[11] Ministry of Health of Vietnam (2009), "QCVN 01:2009/BYT - National technical regulation on drinking water quality", Hanoi 2009. http://www. fsi.org.vn/pic/files/qcvn-01-2009-byt-ve-nuoc-an -uong.pdf. (in Vietnamese).

[12] Ministry of Health of Vietnam (2009), "QCVN 02:2009/BYT - National technical regulation on domestic water quality", Hanoi 2009. http://www. fsi.org.vn/pic/files/qcvn-02-2009-byt-ve-nuocsinh-hoat.pdf. (in Vietnamese).
[13] Le Thi Vinh, Water environmental quality at the coastal area of Phu Quoc island, Journal of Marine Science and Technology 13(3) (2013) 289-297. https://www.vjs.ac.vn/index.php/jmst.

(in Vietnamese).

[14] Pham Huu Tam, "Coastal Seawater Quality from Data at South Vietnam Monitoring Stations during 2013 -2017”, VNU Journal of Science: Earth and Environmental Studies 34(2) (2018) 95-109. https:// doi.org/10.25073/2588-1094/vnuees.4250.

(in Vietnamese).

[15] Nguyen Dinh Nguyen, Nguyen Dinh Thai, $\mathrm{Vu}$ Van Tich, Vu Viet Duc, Hoang Van Hiep, Characteristics of Seawater Environment and Geochemistry of Surface Sediment in Quang Binh Sea Area (60-100m Depth), VNU Journal of Science: Earth and Environmental Studies 34(4) (2018) 89-97. https://doi.org/10.25073/2588-1094 /vnuees.4309. (in Vietnamese). 